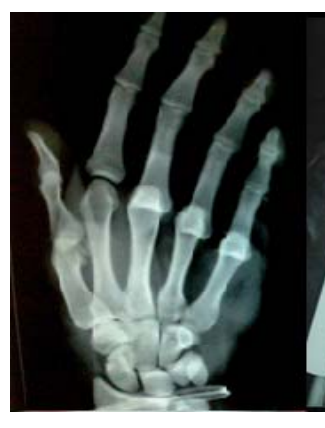

ISSN: $2395-1958$

IJOS 2017; 3(1): 664-668

(C) 2017 IJOS

www.orthopaper.com

Received: 08-11-2016

Accepted: 09-12-2016

Dr. Hari J Menon

Ms Ortho, Professor,

Department of Orthopaedics,

Government Medical College,

Surat, India

Dr. Sandip Patil

Ms Ortho, Consultant

Orthopaedic Surgeon,

Kolhapur, Maharashtra, India

Correspondence

Dr. Hari J Menon

Ms Ortho, Professor,

Department of Orthopaedics,

Government Medical College,

Surat, India
International Journal of Orthopaedics Sciences

\section{Caudal epidural steroids in management of lumbar radiculopathy}

\section{Dr. Hari J Menon and Dr. Sandip Patil}

DOI: http://dx.doi.org/10.22271/ortho.2017.v3.i1j.98

\section{Abstract}

Introduction: Practice of epidural steroid injections have been used in the past in for lumbar radiculopathy. We observed and analysed outcomes of caudal epidural steroid injections in the management of lumbar radiculopathy due to disc herniations.

Methods: In this study, 45 patients with lumbar radiculopathy due to disc herniation between the ages of 18-50 confirmed by MRI were included in the study. All patients were given a suspension of Methyl prednisolone along with local anaesthetic through caudal epidural route and the results were analysed. Results: Majority of the patients [64.5\%] had significant pain relief measured by VAPS, ODI and SLRT and could avoid surgery. 13 patients opted for surgery due to failure of epidural steroid injections. None of the patient had deterioration of pain or disability as compared to pre-injection status.

Conclusion: Patient with predominant radicular pain due to lumbar disc herniation can be considered for treatment with caudal epidural steroids prior to being considered for operative intervention. Caudal epidural steroids offer a cost effective and low risk alternative to surgery.

Keywords: Caudal epidural steroid injection, lumbar radiculopathy, disc herniation

\section{Introduction}

The approach to the management of lumbar radiculopathy has undergone substantial change in recent decades. Lumbar radiculopathy can often present as a difficult problem to solve.

Since Macnab ${ }^{[18]}$ described the technique of nerve-root injection more than four decades ago, numerous investigators have reported on its value in treating patients with radicular pain [16, 20], ${ }^{\text {[21] }}$ Most authorities agree that the initial treatment of acute radicular pain in the low back should be bed rest, anti-inflammatory medication, and physical therapy $[10,18,21]$. However, many patients who have been so treated have persistent pain and seek further intervention. An epidural injection of steroids is a popular treatment method, despite the fact that the short and long-term results of such therapy remain controversial ${ }^{[4,9,10,21]}$. Because of the relatively low cost and morbidity associated with the injections compared with those associated with an operative procedure, injections are likely to be cost-effective if they allow even a small percentage of patients with lumbar radiculopathy to avoid operative intervention. The principle behind this technique is to reduce inflammation of the nerve root by injecting steroid and thereby reducing intensity of pain.

The purpose of the present study was to critically examine the efficacy of caudal epidural corticosteroids in a prospective manner to determine their efficacy in alleviating radicular pain and if they could obviate the need for operative intervention in patients with lumbar radiculopathy.

\section{Materials and Methods}

In this study we have prospectively evaluated forty five patients with significant radicular symptoms after giving them caudal epidural steroid. All the patients for this study were obtained from a single institute. All patients between 18 to $50 \mathrm{yrs}$, irrespective of sex who had radicular pain with a lumbar disc herniation confirmed by magnetic resonance imaging were included. Only those patients with radiculopathy for more than 3 months and demonstrating positive SLRT [within 30-60 degrees] who have completed 6 weeks of conservative management including anti-inflammatory medication, rest and physical therapy were included. 
All patients were prospectively followed over one and half year.

Patients with more of back pain component, progressive neurological deficit and lack of radiographically detectable abnormality were excluded.

All patients who met the criteria were enrolled in the present study, and a total of 45 agreed to participate. There were 29 men and 16 women. All patients were prospectively assessed with an examination and a questionnaire. The self-assessment questionnaire included a Visual Analog Pain Scale of 0 to 10 for assessment of current back and lower-extremity pain and an Oswestry Disability Index was employed to quantitate the level of function (on a 0 to 100-point scale, in which a higher score represented greater disability).After signing an informed consent enrolled patients were taken for caudal block.

\subsection{Injection}

- All patients were given caudal block under fluoroscopic guidance as initial reports have reported improper needle placement in many as $25 \%$ to $40 \%$ of the cases. All injections were given by same person to avoid inter observer bias.

- All patients were given $4 \mathrm{ml}$ of inj. Methylprednisolone acetate $(40 \mathrm{mg} / \mathrm{ml})$ and $2 \mathrm{ml}$ of adrenaline free lignocaine $2 \%$ and added $24 \mathrm{ml}$ of normal saline to make a volume of $30 \mathrm{ml}$.

\subsection{Technique}

The patients were placed prone on a radiolucent table under Carm control. The procedure was carried out with a strict aseptic technique. The prone position is often easiest in the adult, as fat tends to move away from the mid-line and landmarks are easier to find. The caudal space is made more prominent by asking the patient to internally rotate their ankles.

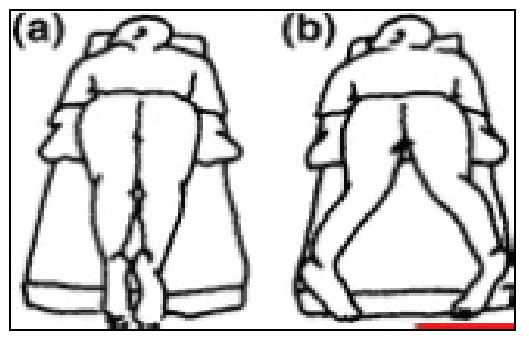

Position (a) causes contraction of the gluteal muscles.

Position (b) allows relaxation of gluteal muscles.

The landmarks were palpated. The sacral hiatus and the posterior superior iliac spines form an equilateral triangle pointing inferiorly. The sacral hiatus can be located by first palpating the coccyx, and then sliding the palpating finger in a cephalad direction until a depression in the skin is felt.

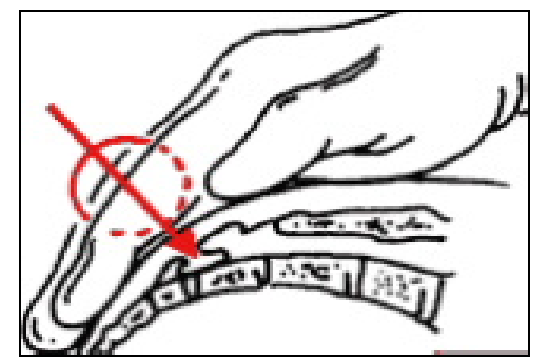

Once the sacral hiatus was identified a 22 gauge short bevelled cannula or needle with the bevel of the spinal needle facing ventrally was directed at about $45^{\circ}$ to skin and inserted till a "feeling of give way" was felt as the sacro-coccygeal ligament was pierced. Using fluoroscopic guidance, we confirmed needle placement and the needle was then carefully directed in a cephalad direction at an angle approaching the long axis of the spinal canal.

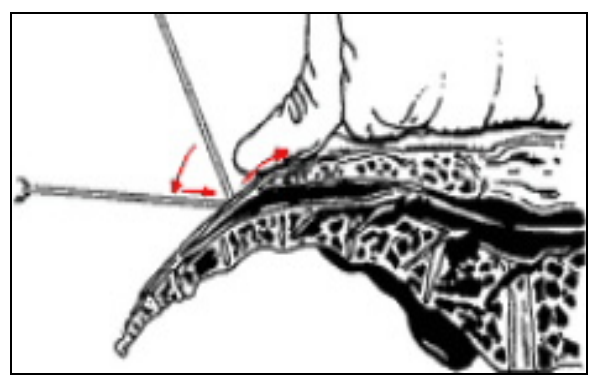

The needle was aspirated looking for either CSF or blood. Then we injected $5 \mathrm{ml}$ of nonionic contrast dye to confirm placement. After Moving the $\mathrm{C}$-arm into the anteroposterior position, looked for the characteristic "Christmas tree" pattern of epidural flow. Once the correct contrast pattern was obtained, injected the patient with $30 \mathrm{ml}$ volume containing 4 $\mathrm{ml}$ of methylprednisolone acetate, $2 \mathrm{ml}$ of adrenaline free lignocaine $2 \%$ and $24 \mathrm{ml}$ of normal saline.

We performed thorough neurological examination, which included documentation of motor strength and complete examination of sensory system dermatome wise. All patients were given non-steroidal anti-inflammatory drugs to be taken as continuously for 3 days and then as required. All patients were subjected to physiotherapy in the form of McKenzie therapy. None of the patients was told to change their occupation. All patients who were showing improvement (VAPS $<5$ ) were told to resume to their routine occupation with minimal lifestyle modification. Patients were followed up serially at 10 days to 1 month, 1 to 3 months, 4 to 6 months, 9to 12 months and 15 to 18 months. At all follow ups, patients were asked to fill both Oswestry Disability Index, and Visual Analog Pain Scale and a thorough physical and neurological examination was carried out.

The questionnaire and examination were completed at presentation and at every subsequent clinical visit. Follow-up was carried out after treatment at ten days to one month, at one to three months, at three to six months, at nine months to one year and at fifteen to eighteen months.

\section{Results}

In our study we had 45 patients including 29 males and 16 females. 3 patients were lost to follow up which included 1 male and 2 female. 30 patients had L4-5 disc prolapse while 15 had L5-S1 disc prolapse. None of patients had a higher level disc disease. All patients were in range of 23 years to 48 years [mean35.37] and had completed at least 1 month of conservative management [non operative management including anti-inflammatory medication, physical therapy, and activity modification for at least six weeks without adequate benefit.] with range between 1 month to 4 months [mean2.29 months]. 23 were heavy workers whereas rest were having a more sedentary lifestyle. Of the 45 patients, 18 patients had no neural deficit while 7 patients had both motor and sensory deficit. None of them had weakness less than grade II. 
All patients were serially followed up to 18 months [mean 7.71 months]. We analyzed the patients on the basis of Oswestry Disability Index, Visual Analog Pain Scale serially along with physical and neurological examination. The responses to the injections demonstrated a significant improvement in all studied parameters compared with the baseline.

Lower-extremity pain as assessed by straight leg raising test improved significantly compared with the baseline, in all follow-up periods. Mean SLR [straight leg raising test] pre injection was $40^{\circ}$ (38.70) while it showed a significant decrease to mean of $60^{\circ}$ at 1 month period, $70^{\circ}$ at 3 month period and $80^{\circ}$ at 1 year. The patients who required surgery later had a similar values pre injection but significant deterioration at 3 month interval as compared to other group. Neurological function at the time of presentation and at the final follow-up examination was evaluated. The patients with sensory deficit improved early as compared to those with motor deficit. But even patients with motor weakness steadily improved over time. Mean duration for sensory recovery was 3.4 months while motor recovery was 5 months.

Table I: Neurological Assesment

\begin{tabular}{|c|c|c|c|c|}
\hline \multirow{2}{*}{ Function } & \multicolumn{4}{|c|}{ No. of patients } \\
\cline { 2 - 5 } & Pre & \multicolumn{2}{|c|}{ Post ESI Recovery (final f/u) } \\
\cline { 3 - 5 } & ESI & Full & Partial & None \\
\hline Motor & 08 & 02 & 02 & 04 \\
\hline Sensory & 12 & 08 & 02 & 02 \\
\hline Both Motor \& Sensory & 07 & 02 & 01 & 04 \\
\hline
\end{tabular}

The responses to both back and lower-extremity pain were compared with the baseline using Visual Analog Pain Scale. It demonstrated a significant decrease in all patient at all follow-up periods. Mean VAPS [Visual Analog Pain Scale] pre injection was 6.82 while it showed a significant decrease to mean of 4.02 at 1 month period, 3.1 at 3 month period and 2.5 at 1 year.

The patients, who required surgery later, had similar values preinjection but significantly increased values at 3 month interval. Even these patients had initial favorable response in early post injection period.

Function, as assessed with the Oswestry Disability Scale, also improved significantly, compared with the baseline at all follow-up periods. Mean ODI [Oswestry Disability Index] pre injection was 60.31 while it showed a significant decrease to mean of 35.7 at 1 month period, 28.2 at 3 month period and 16.4 at 1 year.

Table II: ODI Assesment

\begin{tabular}{|c|c|c|c|c|}
\hline \multirow{2}{*}{ Degree } & \multicolumn{4}{|c|}{ No. of patients } \\
\cline { 2 - 5 } & \multirow{2}{*}{ Pre ESI } & \multicolumn{3}{|c|}{ Post ESI } \\
\cline { 3 - 5 } & & 10 days & 3 months & Final follow up \\
\hline $0-10$ & - & - & - & 22 \\
\hline $10-20$ & - & - & 10 & 06 \\
\hline $21-30$ & - & 02 & 14 & 01 \\
\hline $31-40$ & - & 24 & 04 & 09 \\
\hline $41-50$ & - & 09 & 09 & 04 \\
\hline $51-60$ & 31 & 10 & 01 & - \\
\hline $61-70$ & 14 & - & - & - \\
\hline
\end{tabular}

The patients who required surgery later, deteriorated after showing initial improvement earlier. But the improvement in failure group was lesser as compared to successful group.

Table III: Success Rate at Final Follow Up

\begin{tabular}{|c|c|c|c|c|}
\hline & $\begin{array}{c}\text { No of } \\
\text { patients }\end{array}$ & $\begin{array}{c}\text { SLR in } \\
\text { degree }\end{array}$ & $\begin{array}{c}\text { Mean } \\
\text { ODI }\end{array}$ & $\begin{array}{c}\text { Mean } \\
\text { VAPS }\end{array}$ \\
\hline Pre-ESI & 45 & 40 & 60.31 & 6.8 \\
\hline $\begin{array}{c}\text { Post-ESI } \\
\text { Success group }\end{array}$ & 29 & 85 & 16.4 & 2.5 \\
\hline $\begin{array}{c}\text { Post-ESI } \\
\text { Failure group }\end{array}$ & 13 & 51.5 & 40 & 4.5 \\
\hline
\end{tabular}

All the patients who continued to show improvement at 3 months were free of symptoms for long. The patients who had a successful epidural steroid injection tended to be older than those for whom the injection failed (mean age, forty-four compared with thirty-nine years

Few complications were seen in our study. Most common being pain at local site which was seen in 5 patients $(11 \%)$. It was short lasting and usually resolved in 2 days. The other being headache in 3 patients $(7 \%)$. None of the patient had any major complication reported earlier. This suggests that it was indeed a safe procedure if properly performed.

Of the 45 patients, 3 patients were lost to follow up while 42 patients are continuing to follow up. Of the 42 patients 13 considered the treatment with the epidural steroid injection a failure and had a subsequent discectomy. Continued pain was the predominant reason mentioned by the patients for the failure of the injection; however, one stated that a persistent neurological deficit in the form of weakness was also an important factor in the decision to proceed with the discectomy. Of the patients who required discectomy, 6 were males 7 were females. 6 of them were heavy labourer while 7 had more sedentary lifestyle.

We analyzed data and found that $64.5 \%$ of patients avoided surgery at final follow up even if all patients who were lost to follow up would have undergone discectomy. The success of injection was not adversely affected by neurological deficit before injection.

No patient showed deterioration in radicular pain or neurological deficit as compared to pre ESI status during all follow up period.

\section{Discussion}

A number of studies have evaluated epidural steroid injections for the nonoperative treatment of lumbar disc herniation. Some investigations, including a number of randomized, prospective, and blinded studies in which patients were followed for periods ranging from weeks to one year ${ }^{[11,23]}$, showed epidural steroid injection to be beneficial. However, other comparative randomized and prospective studies of epidural steroid injection demonstrated no substantial effect on the clinical outcome $[9,15]$. Some obstacles to meaningful comparisons between ESI studies include differences in patient populations, amount and type of steroid used, volume injected, the use of local anesthetics and/or other analgesics, route of injection, and/or number of injections. 
The major flaw in all published interlaminar ESI outcome studies has been the lack of fluoroscopic confirmation of injection site accuracy. In studies assessing the accuracy of caudal, lumbar and cervical interlaminar ESI, investigators have repeatedly shown the necessity of fluoroscopic confirmation to ensure both entry into the epidural space and spread of injectate to the affected area. In our study, all the injections were under fluoroscopic guidance in contrast to most recent studies ${ }^{[19]}$.

In our study we included those patients who did not respond to conservative management for six weeks. Six weeks times after the onset of symptoms have been chosen since many patients have spontaneous improvement along with a decrease in the size of the disc herniation during this period. In fact, a study involving follow-up magnetic resonance imaging of patients who had improvement within six weeks after ESI demonstrated a substantial decrease in the size of the disc herniations [5]. We have used $30 \mathrm{ml}$ volume of injection as higher volumes are needed to reach the required level in caudal approach. Further Evans observed that higher volume causes displacement of the posterior and lateral aspects of the dural sac, and reasoned that the physical displacement of the neural elements caused by the injected fluid may lead to stretching and lyses of neural adhesions and even to anaesthesia from compressive effects ${ }^{[13]}$

In the present study, the total number of patients who did not undergo discectomy is 29 and the total number in whom the epidural steroid injection failed was 13. Thus, the rate of failure of treatment during the course of the present study was $30 \%$ ( 3 patient lost in follow up not included), which is similar to the $26 \%$ rate predicted in a previous report ${ }^{[7]}$.

Neurological findings at the final follow-up evaluation showed that sensory deficit resolve more than motor deficit and we also found that rate of improvement was faster in those with only sensory deficit. Motor deficit also showed improvement but not in as many patients as those with sensory deficit. This data is not different from recent studies of patients with a nonoperatively treated disc herniation also showed neurological improvement with regard to motor and sensory changes although some of the patients who presented with sensory or motor changes still had some abnormalities at one year ${ }^{[3,12]}$. So we cannot definitely say whether this was due to epidural steroid or natural history of disease as in itself disc disease has favorable prognosis in most patients. Further, although one might expect surgery to be superior to nonoperative care of patients with stable neurological deficits, this has not been supported by the available literature. Hakelius ${ }^{[14]}$, Weber ${ }^{[22]}$, the Maine Lumbar Spine Study ${ }^{[2]}$, and Saal demonstrated that stable radicular weakness resolves equally well regardless of treatment. In a more recent pilot study of sixty patients with stable paresis associated with lumbar disc herniation, Dubourg et al ${ }^{[12]}$ also found no difference between neurological recovery following surgical management and that following medical management. This finding is in contrast to the situation for a patient with a progressive neurological deficit and cauda equina syndrome, for whom, the evidence suggests, urgent decompression provides the best functional improvement ${ }^{[17]}$.

We have also studied various parameters such as function as assessed by Oswestry Disability Index, back and lowerextremity pain as assessed using Visual Analog Pain Scale and leg pain as assessed by straight leg raising test, which were also used in other published studies and are comparable with our present study. Table below shows results of the other studies at 3 months post ESI compared with our study.

\subsection{Comparision With Other Similar Study At 3 Months Follow Up}

\begin{tabular}{|c|c|c|c|c|c|c|}
\hline Study & \multicolumn{2}{|c|}{ Positive SLRT } & \multicolumn{2}{c|}{ ODI } & \multicolumn{2}{c|}{ VAPS } \\
\hline & Pre-ESI & Post-ESI & Pre-ESI & Post-ESI & Pre-ESI & Post-ESI \\
\hline Our present study & $100 \%$ & $33 \%$ & 60.31 & 28 & 6.8 & 3 \\
\hline Study by Carette et $_{\text {al }}{ }^{8}$ & $91 \%$ & $49.4 \%$ & 49.6 & 32.2 & 6.56 & 3.89 \\
\hline${\text { Study by Arden } \text { et }_{\text {al }}^{1}}^{1}$ & $90 \%$ & $52 \%$ & 44 & 13 & 52 & 13 \\
\hline
\end{tabular}

Our study found that all parameters had a constant improvement in all patients, while those with failure of treatment still had some improvement initially but deteriorated at 3 months follow up (as depicted by graphs in result section). We therefore suggest that those patients who have persistent pain after 3 months of injection are candidates who will eventually require surgery.

The study did have limitations, particularly because it lacked a specific control group. Secondly, it was not compared with surgical treatment. It is impossible to directly compare the literature on outcomes of surgical discectomy with reports on outcomes of epidural injections because of the numerous differences in surgical technique (e.g., open, "minimally invasive," micro discectomy, and aggressive disc-space curettage); and patient selection criteria (e.g., in many studies, those with severe pain or progressive neurological deficits were not considered candidates for nonoperative treatment) and thirdly the types of noninvasive management varied among the treating therapists before referring patients to our institute for management. Fourthly, follow-up magnetic resonance images of the patients in the epidural steroid injection group, to assess changes in disc morphology and the possible effects of the injection, may be valuable. Such a study could help us to understand whether the success of epidural steroid injections is related to resorption of the herniated disc or whether the patients still have a sizable disc herniation and their clinical improvement is due to modulation of the inflammatory response to the herniation.

The present study supports the use of epidural steroid injection in patients with continued severe symptoms after six weeks of noninvasive treatment because most of the patients who received such an injection had a fairly rapid decrease in the symptoms. The degree of improvement was seen in all parameters at all intervals. The patients in whom the epidural steroid injection failed and who subsequently underwent discectomy had persistent pain at 2 to 3 month interval so we can safely know which patients would respond and which won't if we assess patient at 3 month period.

We don't exactly know why the patients had continued relief for so long even though action of local steroid generally last 
for three weeks as reported in previous studies. Probable explanation could be the fact that lumbar disc disease in itself has a very favorable natural history and most patients operated or not have similar outcome. This has been well documented in previous reports ${ }^{[6,14]}$.

Analyzing the data it is quite obvious that caudal epidural steroid is highly efficacious in lumbar radicular pain due to disc herniation and it has a significant role to play in obviating the need for surgery.

\section{Conclusions}

Caudal epidural steroids are effective in treatment of radicular pain due to lumbar disc herniation.

A caudal epidural steroid causes improvement in all functional parameters of the patients.

Patient with predominant radicular pain due to lumbar disc herniation at one or two levels can be considered for treatment with caudal epidural steroids prior to being considered for operative intervention.

Caudal epidural steroids offer a cost effective and low risk alternative to surgery.

\section{References}

1. Arden NK, Price C, Reading I, Stubbing J, Hazel-grove J, Dunne $\mathrm{C}$ et al. WEST Study Group. A multicentre randomized controlled trial of epidural corticosteroid injections for sciatica: the WEST study. Rheumatology (Oxford). 2005; 44:1399-1406.

2. Atlas SJ, Keller RB, Wu YA, Deyo RA, Singer DE. Longterm outcomes of surgical and nonsurgical management of sciatica secondary to a lumbar disc herniation: 10 year results from the Maine lumbar spine study. Spine. 2005; 30:927-935.

3. Balague F, Nordin M, Sheikhzadeh A, Echegoyen AC, Brisby H, Hoogewoud HM et al. Recovery of severe sciatica. Spine. 1999; 24:2516-24.

4. Bogduk N. Epidural steroids. Spine.1995; 20:845-848.

5. Buttermann GR. Lumbar disc herniation regression after successful epidural steroid injection. J Spinal Disord Tech. 2002; 15:469-76

6. Campbell's operative orthopaedics tenth edition volume II.

7. Carette S, Leclaire R, Marcoux S, Morin F, Blaise GA, StPierre A et al. Epidural corticosteroid injections for sciatica due to herniated nucleus pulposus. N Engl J Med. 1997; 336:1634-40. Bone Joint Surg Am. 1985; 67:63-66.

8. Carette S, Leclaire R, Marcoux S. Epidural corticosteroid injections for sciatica due to herniated nucleus pulposus. N Engl J Med. 1997; 336:1634-1640.

9. Cuckler JM, Bernini PA, Wiesel SW, Booth RE Jr, Rothman RH, Pickens GT. The use of epidural steroids in the treatment of lumbar radicular pain. A prospective, randomized, double-blind study. J Bone Joint Surg Am. 1985; 67:63-6

10. Derby R, Kine G, Saal JA, Reynolds J, Goldthwaite N, White $\mathrm{AH}$ et al. Response to steroid and duration of radicular pain as predictors of surgical outcome. Spine.1992; 17(Supplement 6):176-S183,
11. Dilke TF, Burry HC, Grahame R. Extradural corticosteroid injection in management of lumbar nerve root compression. Br Med J. 1973; 2:635 -7.

12. Dubourg G, Rozenberg S, Fautrel B, Valls-Bellec I, Bissery A, Lang $\mathrm{T}$ et al. A pilot study on the recovery from paresis after lumbar disc herniation. Spine. 2002; 27:1426-31.

13. Evans W. Intrasacral epidural injections in the treatment of sciatica. Lancet. 1930; 2:1225-1259.

14. Hakelius A. Prognosis in sciatica: a clinical follow-up of surgical and nonsurgical treatment, Acta Orthop Scand. 1970; 129(suppl): 1 .

15. Klenerman L, Greenwood R, Davenport HT, White DC, Peskett S. Lumbar epidural injections in the treatment of sciatica. Br J Rheumatol. 1984; 23:35-8.

16. Krempen JF, Smith BS. Nerve-root injection. A method for evaluating the etiology of sciatica. J. Bone and Joint Surg. 1974; 56-A:1435-1444.

17. Kushner FH, Olson JC. Retinal hemorrhage as a consequence of epidural steroid injection, Arch Ophthalmol, 1995; 113:309.

18. Macnab I. Negative disc exploration. An analysis of the causes of nerve root involvement in sixty-eight patients. J Bone and Joint Surg. 1971; 53-A:891-903.

19. Riew KD, Yin Y, Gilula L, Bridwell KH, Lenke LG, Lauryssen C, Goette K. The effect of nerve-root injections on the need for operative treatment of lumbar radicular pain. A prospective, randomized, controlled, double-blind study. J Bone Joint Surg Am. 2000; 82:1589 -93.

20. Stanley D, McLaren MI, Euinton HA, Getty CJ. A prospective study of nerve root infiltration in the diagnosis of sciatica. A comparison with radiculography, computed tomography, and operative findings. Spine. 1990; 15:540543.

21. Van Tulder MW, Koes BW, Bouter LM. Conservative treatment of acute and chronic nonspecific low back pain. A systematic review of randomized controlled trials of the most common interventions. Spine. 1997; 22:2128-2156.

22. Weber H. Lumbar disc herniation: a controlled, prospective study with ten years of observation, Spine. 1983; 8:13

23. Yates DW. A comparison of the types of epidural injection commonly used in the treatment of low back pain and sciatica. Rheumatol Rehabil. 1978; 17:181-6. 